\title{
The LEDs luminance distribution measurement quality dependency on image focusing
}

\author{
Dariusz Czyżewski* \\ Electrical Power Engineering Institute, Warsaw University of Technology, Koszykowa 75, 00-662 Warszawa
}

Received December 22, 2020; accepted December 23, 2020; published December 31, 2020

\begin{abstract}
Luminance measurements are used in a vast range of lighting technology fields. The author's research has proved that measuring the luminance distribution on a light source surface is the most challenging part of this process. The research has been conducted for a commercially available digital luminance distribution meter, the goal being to analyze the influence of image focus settings and exposure parameters on measured luminance values. It has been concluded that incorrect image focus and inadequately matched exposure parameters (distance from the workpiece) contribute to quantitative information changes regarding luminance distribution on a LED surface and affect the precision of the maximum luminance determination.
\end{abstract}

Light-emitting diodes (LED) are among the most dynamically developing light sources these days. Many types of LEDs have been developed over the last few years. However, due to low unit power of single LEDs (typically $1 \mathrm{~W}$ for high power LEDs), LED matrices containing from a few to even over a hundred LEDs (e.g. in road lighting) are used [1] whenever we wish to replace classic light sources (light bulbs - in interior lighting [2], discharge lamps - interior lighting [3] and exterior lighting [4]). Such constructions are typically of quite a considerable size (especially visible in high power road luminaires) [5]. Another concern is the need to dissipate a considerable amount of heat (for high-power LEDs) while the construction of heat spreaders additionally increases the luminaire's size. Another common practical problem is the repeatability of color of individual LEDs [6] and the way of determining correctly the color rendering index [7]-[9] for this type of light sources. Additionally, one should also bear in mind the possibility of glare from multi-source LED luminaires [10] as well as the need to disperse the heat emitted by high-power LEDs.

Luminance is one of the photometric parameters which is the most important in the process of luminaire design. The understanding of luminance distribution on a light source surface is the basic parameter for an optical system designer. However, LED manufacturers do not mention this parameter - such information cannot be found in light source catalogues. Additionally, there are very few studies on how the range and distribution of luminance change the surface of diodes and it is difficult to access studies of LED, LED COB or OLED luminance distributions [11-

\footnotetext{
*E-mail: dariusz.czyzewski@ien.pw.edu.pl
}

13]. On the one hand, LEDs are relatively new light sources and on the other hand, extremely expensive and precise measuring equipment is required for luminance studies [14-18]. A proper way of dissipating heat emitted by LEDs should be also ensured during the tests.

At the current level of the author's research, it has been decided to highlight the influence of image focusing on measurement results of luminance distribution on a LED surface. This study presents the author's own experience and observations on proper execution of such measurements. It also discusses how other scientists conduct such measurements [19]. The article also presents the concept of luminance photometry.

Luminance photometry is widely used in many fields of light technology. Such research has started to be performed quite extensively since the introduction of matrix luminance meters. Luminance photometry is often used to measure luminance distribution in the interiors. Figure 2 presents the examples of such measurements for a selected room (Fig. 1). It has to be stressed that good lighting conditions inside the room enable to do simple and easy focusing on an object. However, when measuring luminance distributions on a road illuminated at night, slightly more difficult conditions for image focus are encountered due to low levels of roads illumination (luminance of $0.3-2.0 \mathrm{~cd} / \mathrm{m} 2$, lighting intensity of 5.0 $30.01 x$. Figure 4 presents a view of the model road (Fig. 3 ) and luminance distribution measurements. In this case we see the road and by focusing on its image and using some experience, the focus of the image can be set precisely. Thanks to this, such measurements are replicable.

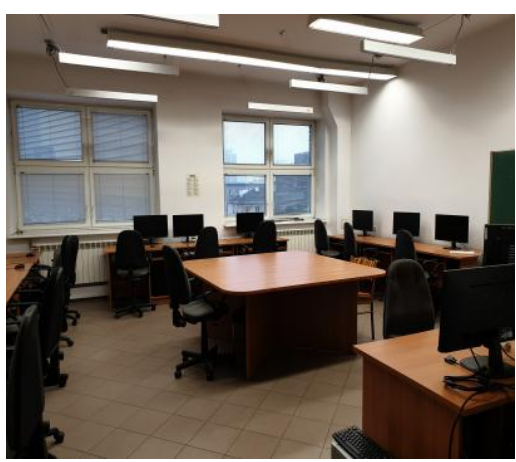

(C) 2020 Photonics Society of Poland 
Fig. 1. View of the room where the measurements were made.

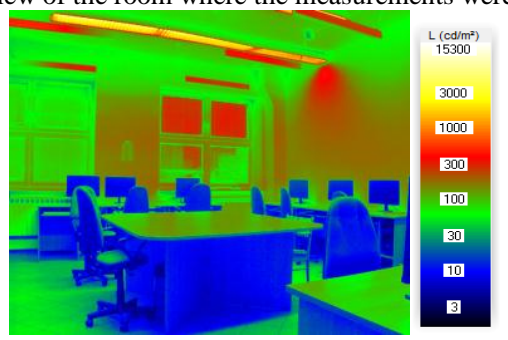

Fig. 2. Luminance distribution on surfaces in the interior.

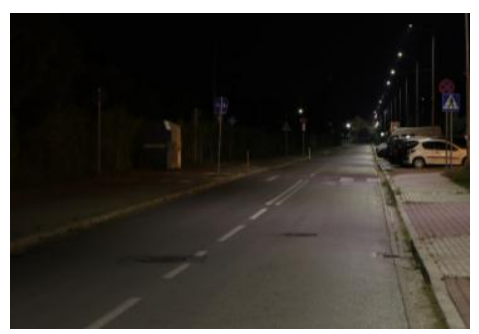

Fig. 3. View of a sample street.

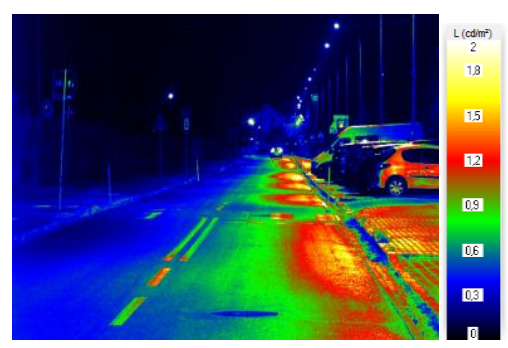

Fig. 4. View of luminance distribution on the sample street.

The case of LEDs is much more complicated. First of all, LEDs are small light sources with luminous surface dimensions of several millimeters. Therefore, for measurements it is necessary to have a dedicated laboratory stand and specialized measuring equipment - a luminance meter with appropriate measuring ranges and lenses. The lens should ensure proper magnification of the measured area so that as much of the meter's photosensitive matrix (CCD or CMOS) as possible is used. All author's tests were conducted in a specially equipped photometric laboratory. Luminance distribution tests were carried out using the objective method with an LMK98-3 color matrix luminance meter. This meter was equipped with a variable focal length lens and macro lens and with neutral gray filters allowing to perform measurements of very high luminance. The measurements were taken after stabilizing the LED performance parameters (which was previously lit out) after a minimum of 30 minutes from switching on. The diodes were measured on a specially designed goniophotometer which enabled measurements in a C- $\gamma$ system [20].

Secondly, as LEDs have very high luminance from a few to over $100 \mathrm{million} \mathrm{cd} / \mathrm{m}^{2}$, it is difficult to focus the image on a light source that is switched on. At this point it is crucial to address the questions how to focus the image on the LED surface correctly and which of the images is correct. Preliminary tests showed that incorrect focus on the tested LED causes significant differences in luminance levels and distribution. Ten popular LEDS from a wellknown manufacturer and used in road luminaires were selected to be discussed in this letter. The LED view is shown in Fig. 5 and the technical parameters are presented in Table 1.

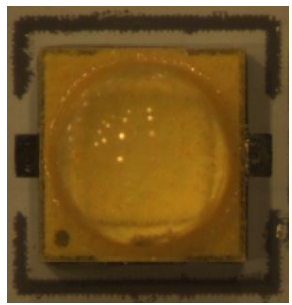

Fig. 5. View of switched-off LED1.

Table 1. Basic technical parameters of diodes subjected to research.

\begin{tabular}{|l|c|}
\hline Technical parameter & $\begin{array}{c}\text { LED } 1 \\
\text { (high power) }\end{array}$ \\
\hline Luminous surface dimensions & $3.45 \times 3.45 \times 1.53 \mathrm{~mm}$ \\
\hline Supply current & $0.35 \mathrm{~A}$ \\
\hline Power & $2.5 \mathrm{~W}$ \\
\hline Luminous flux (for $85^{\circ} \mathrm{C}$ ) & $139 \mathrm{~m}$ \\
\hline CCT & $4000 \mathrm{~K}$ \\
\hline CRI & 70 \\
\hline Thermal resistance & $3^{\circ} \mathrm{C} / \mathrm{W}$ \\
\hline
\end{tabular}

Without knowing the internal structure of this diode and just on the basis of LED 1 view (Fig. 5), it is difficult to predict what distribution of its luminance would be like. It is completely different in the case of determining the luminance of interiors and exteriors where it is possible to predict the luminance distribution visually (compare Fig. 1 and Fig. 2, as well as Fig. 3 and Fig. 4). In the case of LEDs, the problem is on which point of the diode the meter should be focused. Is it the top of the original optical system or the switched-off LED or perhaps the switched-on LED or rather the luminophore surface or its internal structure. Unfortunately, literature does not provide answers to these questions. The difficulty and importance of this research problem can be observed on images of luminance distributions (Figs. 6-9) of the same diode (LED1) measured at different focus settings. It is difficult to indicate which image of luminance distribution is correct without knowing what correct luminance distribution should look like. It is even more difficult when there is no image to compare against. However, in a simple verification of luminance images, one can say that the more focused the image is, the more details are visible on it.

The maximum luminance is an additional parameter that allows us to determine the view accuracy of luminance 
distribution. Column 2 in Table 2 lists the results of maximum luminance measurements for individual cases of image focus. In column 3, the percentage comparison of maximum luminance of individual cases is presented, with reference to the last case which was found the most accurate.

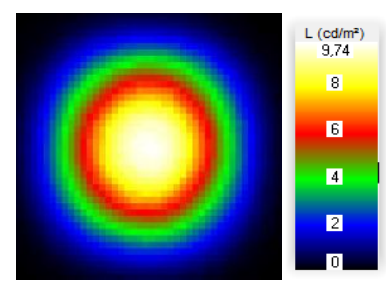

Fig. 6. Case 1 - Luminance distribution on LED1 - bad exposure and focus parameters.

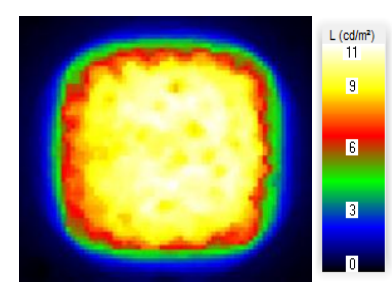

Fig. 8. Case 3 - Luminance distribution on LED1 - focused image but bad exposure parameters.

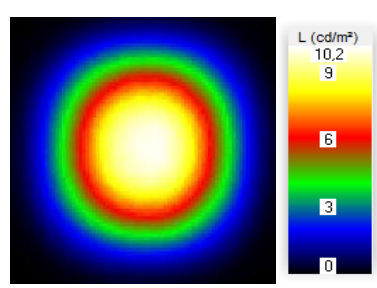

Fig. 7. Case 2 - Luminance distribution on LED1 - bad exposure parameters

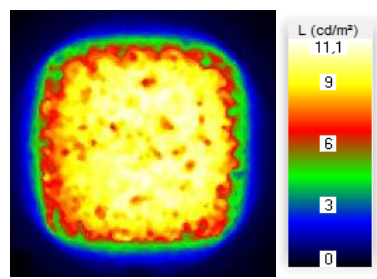

Fig. 9. Case 4 - Luminance distribution on LED1 - focused image on a switched-off LED, correct exposure parameters.
Table 2. Basic technical parameters of diodes subjected to research.

\begin{tabular}{|l|c|c|}
\hline Image focus & $\begin{array}{c}\text { Maximum luminance } \\
\left(\mathrm{Mcd} / \mathrm{m}^{2}\right)\end{array}$ & $\begin{array}{c}\text { Maximum } \\
\text { luminance (\%) }\end{array}$ \\
\hline Case 1 (Fig. 6) & 9.74 & 88 \\
\hline Case 2 (Fig. 7) & 10.20 & 92 \\
\hline Case 3 (Fig. 8) & 11.00 & 99 \\
\hline Case 4 (Fig. 9) & 11.11 & 100 \\
\hline
\end{tabular}

In case 1 , where the maximum luminance is the lowest, the measurement distance and the focus were set incorrectly. This resulted in a change of luminance distribution view and a decrease in maximum luminance. In case 2, the measurement distance was improved but the image was not focused either. In case 3 , the distance was correct and the focus was set on a switched-off LED. The results in case 3 are almost consistent with those of case 4 , where the distance was correct and the focus was set to high magnification with the LED on. Due to the highest maximum luminance and the highest number of details visible in the image, the last case was considered as the reference (the most accurate).

To sum up, poorly selected exposure parameters and incorrect luminance image focus lead to irregularities in determining luminance distribution on a measured LED surface. Additionally, it has been observed that the more accurately the image is measured, the higher the maximum luminance values can be seen on the image. The influence of correct image focus on the results of luminance distribution measurements will be researched further.

\section{References}

[1] C. Xu, H. Cheng, Y. Feng, Front. Optoelectr. 10, 353 (2017); doi: 10.1007/s12200-017-0707-7.

[2] D. Czyzewski, Przeglad Elektrotechniczny 88(11A), 123 (2012).

[3] W.R. Ryckaert, K.A.G. Smet, I.A.A. Roelandts, M. Van Gils, P. Hanselaer, Energ. Build. 49, 429 (2012), doi: 10.1016/j.enbuild.2012.02.042.

[4] X.-H. Lee, I. Moreno, C.-C. Sun, Opt. Expr. 21(9), 10612 (2013), doi: 10.1364/oe.21.010612.

[5] D. Czyzewski, Przeglad Elektrotechniczny 86, 276 (2009).

[6] D. Mozyrska, M. Wyrwas, I. Fryc, Przeglad Elektrotechniczny 93(4A), 232 (2012).

[7] J. Kowalska, I. Fryc, Przeglad Elektrotechniczny 95(7), 94 (2019), doi: 10.15199/48.2019.07.20.

[8] J. Kowalska, Przeglad Elektrotechniczny 93(6), 50 (2017), doi: 10.15199/48.2017.06.13.

[9] K. Houser, M. Mossman, K. Smet, L. Whitehead, J. Illuminating Eng. Soc. North Am. 12(1-2), 7 (2016), doi: 10.1080/15502724.2014.989802.

[10] S. Słomiński, Lighting Res. Technol. 48(5), 573 (2016), doi: $10.1177 / 1477153515596374$

[11] D. Czyzewski, IEEE Lighting Conf. Visegrad Countries (Lumen V4), Karpacz 2016, pp. 1-4,doi: 10.1109/LUMENV.2016.7745523

[12] M. Jongewaard, Proc. SPIE 4775, 86 (2002).

[13] D. Czyzewski, Przeglad Elektrotechniczny R. 84, 129 (2008).

[14] C.D. Galatanu, 2019 Internat. Conf. Electromech. Energy Syst. (SIELMEN), 2019, pp. 1-4.

[15] I. Fryc, E. Czech, Proc. SPIE 5064, 18 (2003), doi: 10.1117/12.501365.

[16] I. Fryc, E. Czech, Opt. Eng. 41(10), (2002), doi: 10.1117/1.1503344.

[17] I. Fryc, Proc. SPIE 4517, 42 (2001), doi: 10.1117/12.435991.

[18] I. Fryc, Proc. SPIE 5064, 38 (2003), doi: 10.1117/12.501381.

[19] M. Moeck, S. Anaokar J. Illuminating Eng. Soc. North Am. 2:3, 211 (2006), doi: 10.1582/LEUKOS.2006.02.03.005.

D. Czyżewski, Crystals 9(12), 645 (2019), doi: 10.3390/cryst9120645. 